\title{
Efeito da instabilidade da superfície no comprimento da passada e ângulo do braço de bebês durante a aquisição da marcha
}

CDD. 20.ed. 796.023

http://dx.doi.org/10.1590/1807-55092014000300481

\author{
Viviani Gusmão Moretto PRÓSPERO* \\ Vanessa Mota ANDRADE-DE CASTRO** \\ Raquel de Melo MARTINS ${ }^{* * *}$ \\ Inara MARQUES ${ }^{* * *}$
}

*Centro Universitário Filadélfia.

${ }^{* *}$ Prefeitura Municipal de Cambé.

***Departamento de Educação Física, Universidade Estadual de

Londrina.

\section{Resumo}

A aquisição da marcha independente foi analisada por meio de um estudo longitudinal, examinando o efeito da instabilidade da superfície no comprimento da passada e ângulo do braço de 11 bebês, com idade média de $12,09 \pm 0,42$ meses. Os bebês foram acompanhados ao longo de quatro meses com avaliações quinzenais. A marcha independente foi realizada sobre duas superfícies - rígida e deformante. 0 comprimento da passada e o ângulo do braço foram analisados por meio da cinemática, utilizando-se o programa APAS. Os resultados apresentaram efeito das sessões e das superfícies para o comprimento da passada e efeito das sessões para o ângulo do braço, indicando alterações no comportamento da marcha nas duas variáveis. Os dados indicam mudanças desenvolvimentais ocasionadas durante o processo de aquisição da marcha independente e sugere que tais alterações precedem a seleção de um padrão ou estratégia mais adequada às demandas do ambiente.

PalavRas-Chave: Marcha independente; Desenvolvimento infantil; Biomecânica; Bebês.

\section{Introdução}

A marcha independente (MI) é um meio de deslocamento do corpo humano e pode ser considerada como um dos maiores desafios a ser enfrentado durante o primeiro ano de vida do bebê. Este desafio é evidenciado por meio dos vários ajustes corporais e controle dos segmentos que sáo necessários para a marcha, tais como: controle postural para vencer a gravidade ao mover o corpo; força de reaçáo ao solo, posição dos braços e integração das informaçóes sensoriais ${ }^{1-4}$. Pode-se dizer que é um processo que envolve muitos sistemas e restriçóes em interação, no qual o bebê aprende a coordenar sua postura na posição vertical associado ao movimento dos segmentos corporais em progressáo para frente ${ }^{1}$. A aquisição da MI, embora seja a forma de locomoçáo mais utilizada pelo ser humano é, na verdade, um comportamento bastante complexo, resultado de um processo dinâmico cujo curso desenvolvimental se altera constantemente, permitindo que os bebês estabeleçam novas relaçôes com o mundo exterior, aprimorando tanto o seu comportamento locomotor quanto ganhando autonomia no ambiente ${ }^{5}$.
As crianças com desenvolvimento típico adquirem a marcha independente por volta de 12 meses de idade ${ }^{3-6}$, sendo definido seu início quando a criança é capaz de executar de cinco a oito passos consecutivos, sem apoio, no ambiente ${ }^{6-7}$. Após esse marco, o bebê deve passar por um período de transiçáo, de aproximadamente dois meses para a aquisiçáo da locomoçáo estável ${ }^{8}$.

O início da MI é caracterizado pelos pés afastados, quadris e joelhos flexionados promovendo, assim, uma base mais larga ${ }^{9-10}$ que diminui gradualmente, com o avanço da idade e experiência. Ao mesmo tempo, os bebês mantêm os braços levantados em guarda alta, que abaixa gradativamente, dando origem aos movimentos recíprocos de balanço dos braços. Há alteraçóes, também, no comprimento e na velocidade da passada, fazendo emergir um padrão mais estável de caminhar ${ }^{5,7,9}$. Ou seja, os bebês se encontram em um período no qual as mudanças são abundantes e necessitam explorar seus recursos biomecânicos, especialmente o comportamento dos membros superiores e inferiores, que se destacam exercendo um papel funcional na aquisição da $\mathrm{MI}^{1}$. 
Há vários estudos que enfatizaram o papel dos membros inferiores na MI, investigando variáveis tais como velocidade de progressão, a cadência, o comprimento de passada, a largura da base e a aceleração $0^{1,5,10-15}$, que, em sua grande maioria, descrevem as alteraçóes ocorridas no decorrer do tempo, buscando um maior entendimento desse importante marco motor no desenvolvimento humano.

O papel desempenhado pelos membros superiores também é destacada em diferentes estudos, ressaltando que a posição dos braços é considerada como uma característica importante que colabora para o controle da postura do corpo, melhorando a eficiência da marcha $a^{5,9,16-19}$.

Vale lembrar que a aquisição da MI não ocorre no mesmo ambiente e, assim os bebês se encontram envolvidos em um processo de selecionar estratégias e adaptaçóes adequadas da marcha em razão de variações do ambiente. Diferentes situações ambientais podem impor novas restriçóes que potencializam modificaçôes tantos nos parâmetros quanto nos padrôes da MI, regredindo o padrão quando executada em uma superfície com inclinação ${ }^{20-21}$, ou mudanças nos parâmetros (quantidade de comprimento da passada) quando em superfícies de diferentes alturas nesse ponto é que se insere o papel das pesquisas cujo modelo é baseado nas restrições. Alguns estudos foram conduzidos dentro de uma perspectiva na qual as restriçôes ambientais podem alterar dinamicamente o desenvolvimento tanto no que se refere aos parâmetros quanto aos padrốes da MI.

Em um estudo de $\mathrm{ADOLPH}^{20}$, conduziu um estudo em que bebês foram fortemente influenciados pela

\section{Método}

\section{Participantes}

Participaram deste estudo 11 bebês, sendo quatro meninas e sete meninos, com idade cronológica de $12,09( \pm 0,42)$ meses, recrutados de uma creche pública do município de Londrina - PR. A direção e os pais foram contatados, permitindo a participação dos bebês no estudo. Os critérios de seleção utilizados foram: serem capazes de realizar oito passos independentes ${ }^{26}$, serem nascidos a termo e apresentar peso no nascimento maior que $2.500 \mathrm{~g}$.

A condução do estudo foi autorizada pelo Comitê de Ética da Universidade local, sob o parecer $n^{\circ}$ 211/06, CAAE n ${ }^{\circ}$ 0161.1.268.000-06, obedecendo restrição do ambiente, apresentando uma regressão do padrão andar para o engatinhar quando submetidas a uma inclinaçáo da plataforma utilizada para a locomoção. VereijKen et al. ${ }^{21}$ realizaram estudo com bebês frente à perturbaçáo com cargas no quadril, tornozelo e ombro. Os resultados mostraram alteraçôes no comprimento da passada entre as condiçóes, parâmetros de largura de passada e rotação do ângulo do pé, todavia ao final das sessóes os bebês se adaptaram as mudanças e melhoraram com a experiência.

No estudo de Theveniau et al. ${ }^{22}$ verificaram o efeito das roupas durante a aquisição da marcha de bebês. Os resultados revelaram efeitos significativos de diferentes tipos de roupas em velocidade e comprimento de passada de bebês de seis a 18 meses de experiência na marcha, sugerindo que a roupa usada deve ser cuidadosamente controlada. De maneira geral, esses estudos buscaram verificar alteraçóes no padrão da $\mathrm{MI}$ em razão de mudanças nos parâmetros ou em diferentes situaçôes.

Pode-se entender que as alteraçóes nos parâmetros dos membros superiores e inferiores são características importantes para o processo de aquisição da $\mathrm{MI}^{1,18,20,22-25}$, fornecendo informaçóes relevantes no seu processo de desenvolvimento. No entanto, poucos estudos foram conduzidos considerando as situaçóes de contexto diferentes ao longo do tempo.

A proposta deste estudo foi analisar se a mudança no ambiente pode desencadear alteraçôes no processo de aquisição da MI em bebês, especificamente, no comprimento da passada e ângulo do braço, quando submetidas a duas superfícies diferentes: rígida e deformante. aos critérios de ética em Pesquisa com Seres Humanos, conforme resolução $n^{\circ}$ 196/96.

\section{Tarefa e procedimentos}

A tarefa consistiu na realização da MI dos bebês sobre duas condições de restrição do ambiente: superfície rígida e superfície deformante.

Para a realização das sessôes foi construída uma passarela de madeira em cor preta, com 3,70 m de comprimento, composta de três módulos móveis (FIGURA 1) no qual, dois módulos periféricos com $1,00 \mathrm{~m} \times 1,00 \mathrm{~m} \times 0,16 \mathrm{~m}$ (comprimento, largura e altura, respectivamente) eram acoplados a um módulo 
central medindo $1,70 \times 1,00 \times 0,16 \mathrm{~m}$ (comprimento, largura e altura, respectivamente). $\mathrm{O}$ módulo central foi composto por uma parte fixa em madeira 1,70 x $1,00 \times 0,11 \mathrm{~m}$ (comprimento, largura e altura respectivamente) dentro do qual são encaixados dois segmentos removíveis - um de madeira (superfície rígida) medindo $1,70 \times 1,00 \times 0,05 \mathrm{~m}$ (comprimento, largura e altura respectivamente) e outro de colchonete (superfície deformante) medindo $1,70 \times 1,00 \times 0,05 \mathrm{~m}$ x $28 \mathrm{~kg} / \mathrm{m}^{3}$ (comprimento, largura, altura e densidade respectivamente), permitindo a nivelação da parte central rígida ou deformante nos outros dois módulos.

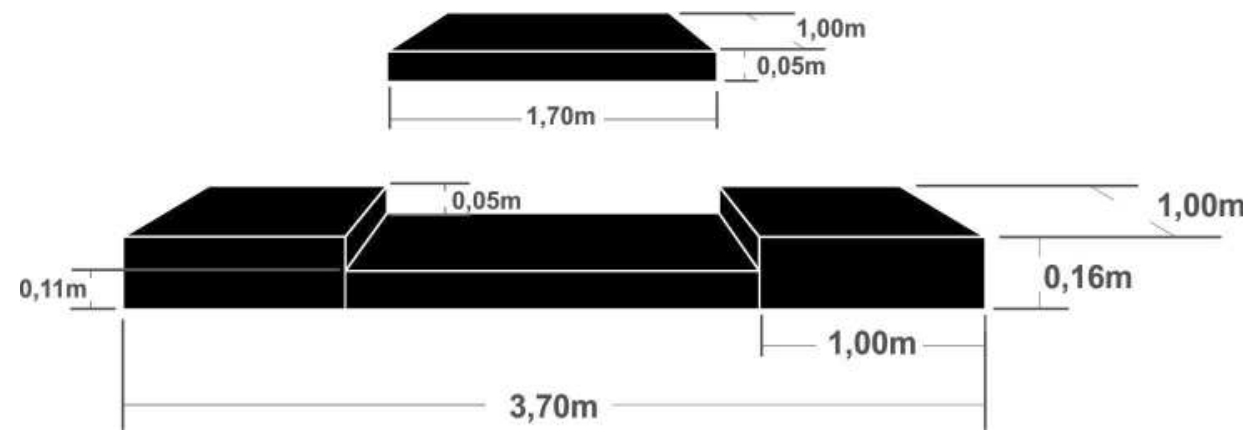

FIGURA 1 - Ilustração esquemática do ambiente experimental.

Para o registro da marcha utilizou-se uma filmadora digital Panasonic, modelo VDR-M53 - 30 hz, posicionada em um tripé a $3 \mathrm{~m}$ de distância e 0,57 $\mathrm{m}$ de altura, perpendicularmente ao módulo central da passarela. Além disso, foi utilizado um calibrador de madeira (1,70m de largura e 0,98 $\mathrm{m}$ de altura), um holofote de 1000 watts, além de tecidos e colchonetes pretos extras, necessários para a calibração e análise cinemática das imagens.

Os bebês foram acompanhados em sessóes quinzenais, individualmente, por aproximadamente quatro meses, computando oito sessóes experimentais.
No dia da sessão, após o período de familiarização com o ambiente, os bebês permaneceram somente de fralda e foram fixados na pele os marcadores refletores, de $1,5 \mathrm{~cm}$ de diâmetro, em cinco centros articulares anatômicos estimados por meio de palpação manual, sendo: 1) quinta articulação metatarsofalangiana; 2) maléolo lateral da fíbula; 3) centro articular do acrômio; 4) côndilo lateral do úmero; 5) processo estilóide da ulna. A ligação entre esses pontos foi utilizada para definir os seguintes segmentos corporais: $\mathrm{pe}^{1-2}$ e antebraço ${ }^{4-5}$ (FIGURA 2).

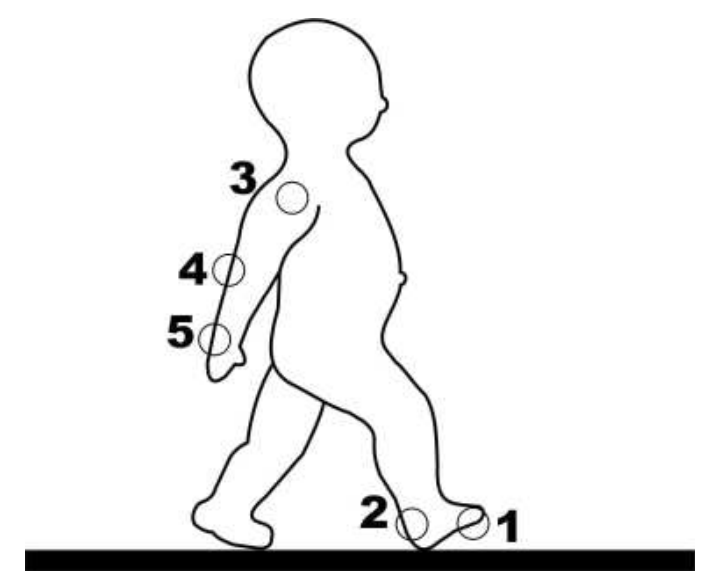

1: quinta articulação metatarsofalangiana; 2: maléolo lateral da fíbula;

3: centro articular do acrômio;

4: côndilo lateral do úmero;

5: processo estilóide da ulna.

FIGURA 2 - Pontos afixados para digitalização e análise (Adaptado de BorTOLAIA ${ }^{27}$ ).

Após esta preparação, os bebês foram estimulados pelos colaboradores a caminhar de forma independente para frente, em direção a sua mãe (ou responsável) que os aguardava com brinquedos colocados no outro extremo da passarela.

\section{Análise dos dados}

As imagens da marcha dos bebês foram analisadas cinematicamente através do programa Ariel Performance Analysis System (APAS 1.4). 
Para a análise dos dados foi considerado o terceiro ciclo de passada dentro da área de análise (centro da plataforma) eliminando-se, assim, as passadas iniciais e finais de cada tentativa. Cada sessão foi composta por três ciclos de passada para cada superfície. O ciclo escolhido para análise foi o que mais se aproximou do valor médio obtido a partir do cálculo da média dos três ciclos analisados, conforme sugerido por SuTHERLAND et al. .

Nesse estudo foi utilizado o sistema de referência bidimensional $(\mathrm{x}-\mathrm{y})$, o qual foi utilizado para o cálculo das variáveis dependentes: comprimento da passada (adquirido pelo cálculo $\Delta s=s f-s i$, onde $s f=$ posição final; $s i$ = posição inicial) e ângulo absoluto externo do braço em relação ao eixo $\mathrm{x}$, fornecidos pelo programa APAS.

\section{Resultados}

\section{Resultados do Comprimento da passada (CP)}

Os resultados indicaram que houve um aumento no CP dos bebês nas duas superfícies ao longo das oito sessóes. No entanto, os valores médios do CP foram maiores na superfície rígida em comparação com a superfície deformante para todas as sessóes.
Para a análise das variáveis independentes foram consideradas: 1) Superfície rígida; 2) Superfície deformante; 3) Número de sessóes.

Para a caracterização da amostra foi realizada análise descritiva identificando-se os valores médios e de desvio-padrão. Como a distribuição dos dados foi normal, foi conduzido o teste Anova para medidas duplamente repetidas (2 superfícies x 8 sessóes). A esfericidade foi testada pelo teste de Mauchly's W, no qual o resultado levou à utilização de correçóes técnicas a partir do teste de Greenhouse - Geisser. Quando se notou efeito significativo em algum dos fatores, utilizou-se o procedimento de Bonferroni para localizar as diferenças. Para todas as análises foi adotado o nível de significância de $\mathrm{p} \leq 0,05$.

Os bebês apresentaram, inicialmente, passadas mais curtas, e ao longo das sessóes aumentaram, nas duas superfícies, os valores do CP. Observou-se um aumento do CP até a quarta sessão para ambas as superfícies; uma diminuição e uma estabilização entre a quinta e a sexta sessão, terminando as sessóes com os valores de 45,45 cm $\pm 9,56$, na superfície rígida e de 40,95 $\mathrm{cm} \pm 9,74$, na superfície deformante.

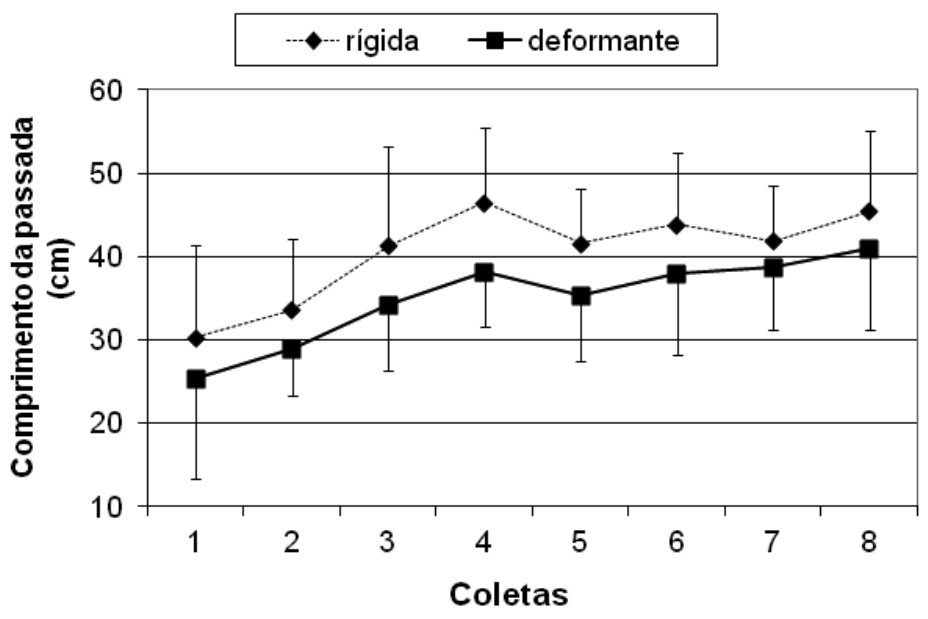

FIGURA 3 - Média e desvio padrão do ciclo representativo no decorrer das oito sessões, nas duas superfícies.

A ANOVA mostrou efeito significativo no fator sessão $(\mathrm{F}=14,133 ; \mathrm{p}=0,01)$ e no fator superfície $(\mathrm{F}=4,50 ; \mathrm{p}=0,05)$ (FIGURAS 4 e 5).

Por meio do "post hoc" de Bonferroni foi possível verificar que a primeira sessão foi diferente das demais $(p=0,01)$, com exceção da segunda sessão $(p>0,05)$. E a segunda sessão foi diferente das demais $(p=0,02)$. Esses resultados indicam que o CP foi aumentando gradativamente ao longo das oito sessóes. No entanto, não houve interação $(\mathrm{F}=0,289 ; \mathrm{p}=0,947)$. 


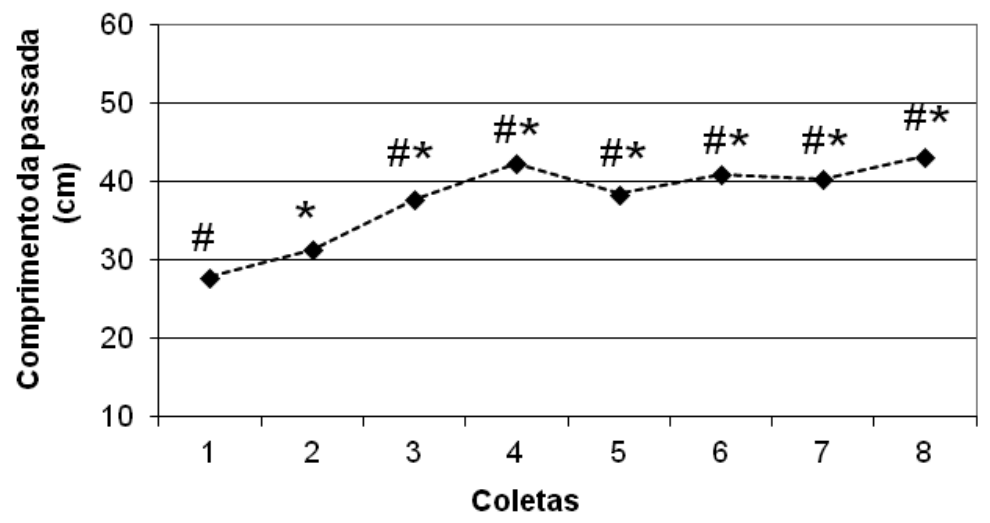

\# $p<0,05$ : diferença significativa da sessão 1 , com as sessões, $3,4,5,6,7$ e 8 .

${ }^{*} p<0,05$ : diferença significativa da coleta 2 com as sessões, $3,4,5,6,7,8$.

FIGURA 4 - Média e desvio padrão dos valores do comprimento da passada (CP), nas duas superfícies.

\section{Comprimento da passada $(\mathrm{cm})$}

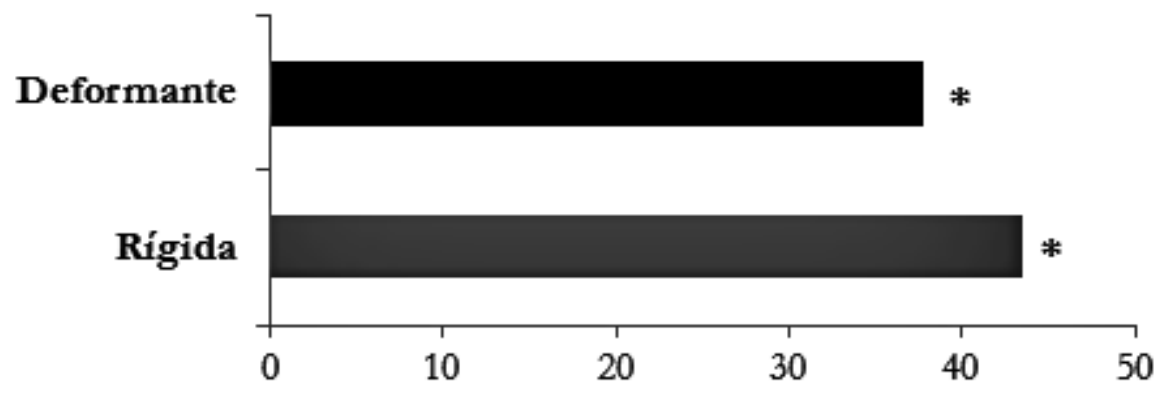

FIGURA 5 - Valores médios do comprimento da passada (CP) na superfície rígida e deformante.

\section{Resultados do ângulo do braço (AB)}

Os resultados relacionados ao $\mathrm{AB}$ dos bebês apresentaram alterações em ambas às superfícies, diminuindo no decorrer das oito sessóes. Embora os resultados do $\mathrm{AB}$ e desvio padrão serem semelhantes nas duas superfícies, na superfície deformante esses valores foram maiores ao longo das sessões, com exceção da oitava (FIGURA 6). Os valores iniciaram com $178,69^{\circ} \pm$ $34,00^{\circ}$ e atingiram $143,45^{\circ} \pm 26,30^{\circ}$ na quinta sessão na superfície rígida e com $192,34^{\circ} \pm 25,28^{\circ}$ reduzindose para $156,76^{\circ} \pm 26,53^{\circ}$ na quinta sessão na superfície deformante. Após a quinta sessão, os valores iniciaram uma estabilização, e na última sessão finalizaram com valores de $127,40^{\circ} \pm 25,78^{\circ}$, na superfície rígida e de $121,84^{\circ} \pm 28,30^{\circ}$, na superfície deformante.

A ANOVA indicou efeito significativo no fator sessão $(F=20,78 ; p=0,01)$ (FIGURA 7), mas não indicou efeito significativo no fator superfície ( $\mathrm{F}=$ $1,97 ; \mathrm{p}=0,05)$.

$A$ variável $A B$ não foi sensível à restrição da tarefa, não apresentando diferenças entre as superfícies rígida e deformante. $\mathrm{A}$ análise estatística também não demonstrou interação $(F=0,798 ; \mathrm{p}=0,602)$. 


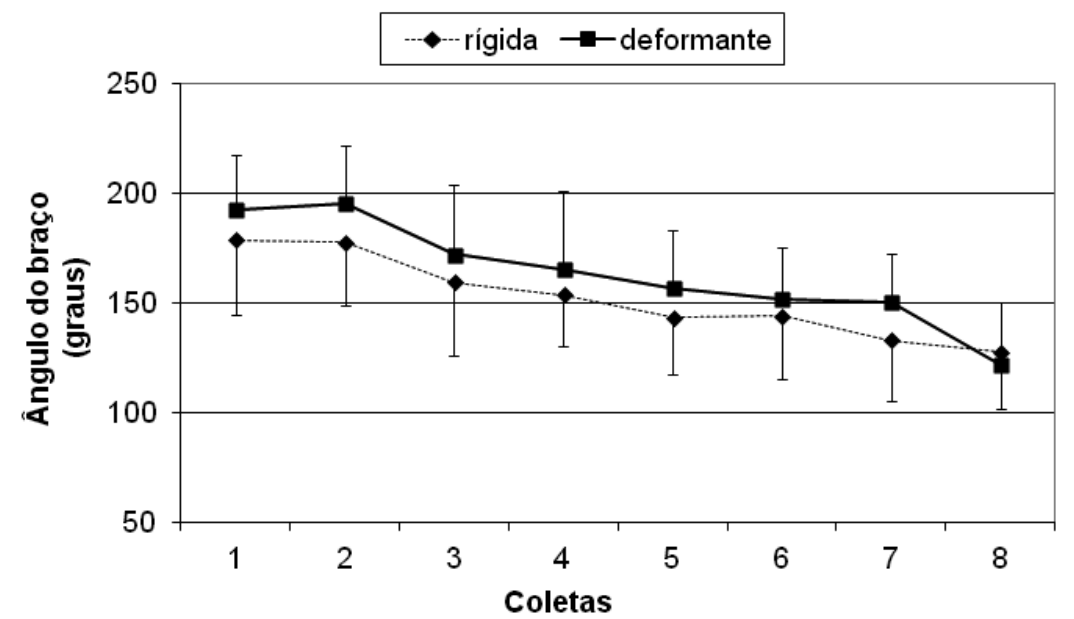

FIGURA 6 - Média e desvio padrão do ângulo dos braços dos bebês durante as oito sessões, nas duas superfícies.

${ }^{*} p<0,05$ : diferença significativa entre sessão 1 e as sessões: 4 , $5,6,7$ e 8 ;

$\# p<0,05$ : diferença significativa entre sessão 2 e as sessões: 4,5,6,7 e 8;

a $p<0,05$ : diferença significativa entre sessão 3 e 8;

b $p<0,05$ : diferença significativa entre sessão 4 e 8;

c $p<0,05$ : diferença significativa entre sessão 5 e 8;

$d p<0,04$ : diferença significativa entre sessão 6 e 8 .

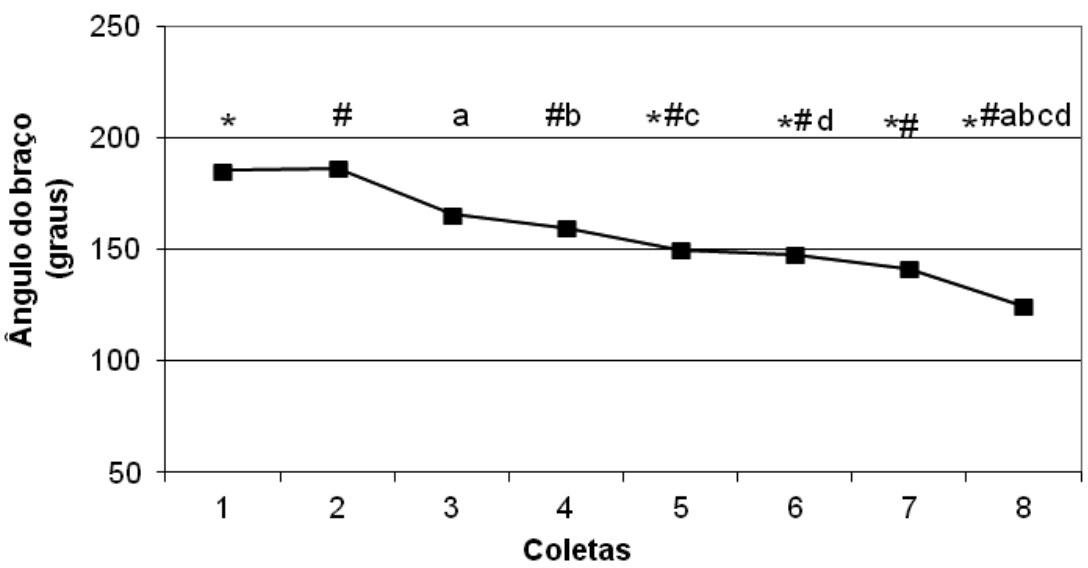

FIGURA 7 - Média e desvio padrão dos valores do ângulo do braço, nas duas superfícies em cada coleta, ao longo do experimento.

\section{Discussão}

A análise dos resultados permitiu identificar que, ao longo das sessôes, os bebês alteraram seus parâmetros da marcha $(\mathrm{CP}$ e $\mathrm{AB})$ de forma semelhante para as duas demandas ambientais.

Com isso, pode-se perceber que houve uma progressão desenvolvimental no fator CP. No entanto, diminui a mesma quando na situação com superfície deformante. Esta progressão desenvolvimental parece coincidir com o primeiro estágio sugerido por BRIL e BRENIÈRE ${ }^{1}$, no qual pode variar de três a seis meses após o início da MI e é caracterizado pelas notáveis alteraçóes em todos os valores dos parâmetros requeridos na marcha. Alguns estudos demonstraram passadas mais curtas e velocidades mais lentas no início da MI em bebês de aproximadamente um ano, aumentando, gradativamente, a amplitude de suas passadas e as velocidades, $5,-10,19,28$.
Este aumento no comprimento das passadas, em nosso estudo, ocorreu na medida em que os bebês adquiriram experiência na marcha, o qual também os auxiliou na melhora da locomoçáo, corroborando com o estudo de Rodrigues et al. ${ }^{28}$, no qual acompanharam longitudinalmente por seis meses a marcha de 32 crianças. Os resultados indicaram que o tempo de prática foi associado a uma variação significativa entre as medidas de velocidade e comprimento da passada dos bebês, indicando uma melhora da locomoção. Segundo SutHerLAND et al. ${ }^{9}$, essas alteraçóes acontecem até o início do segundo ano de vida, diminuindo a intensidade a partir dessa idade. Em nosso estudo, pôde ser observado que, até a quarta sessão ( \pm 2 meses), os bebês apresentaram mais dificuldades para se locomover, embora, aumentando o comprimento das passadas. 
Foi, também, possível observar, uma diminuição e uma estabilização do $\mathrm{CP}$ próximo da quinta sessão para as duas superfícies, o que sugere melhora no padrão da marcha dos bebês obtidos pela experiência do caminhar, auxiliando, consequentemente, na execução da marcha até a oitava sessão.

No que se refere ao valor do CP na comparação entre as duas superfícies, notou-se efeito no fator superfície, ficando evidente o efeito da restrição do ambiente nos resultados do CP com a inclusão da superfície deformante.

Essa alteração do CP na superfície deformante pode ter permitido que os bebês explorassem as diferentes capacidades e possibilidades de padrão locomotor para minimizar a restrição imposta. Dessa forma, sustenta-se que as alteraçóes vistas no $\mathrm{CP}$, na superfície deformante, durante o processo da aquisição da MI, provieram da interação de um subsistema externo, no caso, a restrição do ambiente. Os bebês exploraram e adaptaram o CP por causa da instabilidade provocada pelo ambiente. Sugerindo que a diminuição do CP, na superfície deformante, foi consequência de uma melhor adaptação do comportamento locomotor para adquirir maior eficiência e progredir.

Alguns estudos foram conduzidos buscando verificar o desenvolvimento da locomoção de crianças em situação de superfície inclinada e superfícies diferentes, variando a rigidez ou altura ${ }^{29-30}$. No estudo de Adolph et al. ${ }^{29}$ foi verificado uma regressão do padráo locomotor do andar para o engatinhar, ressaltando, ainda, que as mesmas crianças que alteraram a estratégia para o engatinhar, desciam a superfície inclinada de costas. Outros estudos observaram estratégias adaptativas do CP por parte das crianças na ultrapassagem de obstáculos e altura da superfície de suporte $^{30}$. Gibson et al. ${ }^{31}$ verificaram diferenças no comportamento da locomoção de crianças ao serem submetidas a caminhar sob um colchão de água e uma plataforma rígida de madeira. No entanto, a estratégia de diminuir o comprimento de passada, foi utilizada pelos bebês durante a aquisição da marcha, em nosso estudo, foi específica da superfície deformante, ressaltando, assim, a possibilidade de novos comportamentos poderem emergir pela interação de múltiplos componentes dentro de um contexto ${ }^{12}$. Sendo assim, a adaptação do comportamento motor frente a uma restrição é uma característica inerente do processo de desenvolvimento motor ${ }^{4}$, permitindo aos bebês do nosso estudo maiores possibilidades de explorar soluçôes frente a uma nova tarefa. Vale destacar que, na superfície deformante, a passada foi mais curta quando comparada com a superfície rígida, no entanto, passa por alteraçóes, aumentando no decorrer das sessóes.

Com relação aos resultados do $\mathrm{AB}$, a FIGURA 7 ressalta-se a tendência desenvolvimental dos bebês em apresentar valores maiores do $\mathrm{AB}$ no início da MI. O efeito sessão demonstrou que, a partir da quarta sessão ( \pm 2 meses), os valores do $\mathrm{AB}$ diminuíram significativamente em relação às sessões anteriores, corroborando, com estudos que registraram uma diminuição gradual desta posição ${ }^{18,24}$. Esta elevação dos braços no início da MI parece ser um comportamento utilizado pelos bebês para melhorar a postura e diminuir o desequilíbrio ao caminhar para frente, conforme ressaltado por LEDEBT ${ }^{2}$, além de ser uma tentativa de manter a estabilidade ${ }^{32}$. No presente estudo, não foi observado o aparecimento da oscilaçáo contralateral em nenhum dos bebês, embora todos eles tenham atingido um valor angular menor, correspondendo a uma aproximação dos braços ao lado do corpo. No entanto, PAYNe e IsAacs ${ }^{32}$ já haviam ressaltado que os braços não oscilam no início da MI em oposição à oscilação das pernas.

Desta forma, os valores angulares maiores foram observados somente no estágio inicial da MI nas duas superfícies, e não foram todos os bebês que demonstraram esses valores, havendo nisso coincidências com os estudos de Kubo e Ulrich ${ }^{33}$. Para elas, as alteraçóes observadas na posição de guarda alta, caracterizada pelo estudo de LEDEBT ${ }^{2}$, parece ser uma das opçóes múltiplas, embora temporária, mas não necessária para todos os bebês.

Existem algumas razões que explicam o porquê da maioria dos bebês não terem atingido valores angulares maiores no início da MI neste estudo:

1) Alguns bebês não permaneciam com os braços fixos elevados, oscilando assim o valor angular;

2) Observou-se uma inclinaçáo do tronco para frente dos bebês nas primeiras sessóes e no decorrer do estudo os bebês tornaram-se mais eretos. Esta postura, segundo Yaguramaki e Kimura ${ }^{26}$, pode ajudar os bebês a progredirem na marcha, porém, os bebês oscilavam mais os braços, fazendo com que eles adaptassem os membros superiores para o movimento;

3) O critério dos oito passos independentes pode não ter sido exigente o suficiente para verificação de um $\mathrm{AB}$ maior no início da MI. Há de se destacar que no estudo de LEDEBT $^{2}$, foi convencionado a realização mínima de três passos independentes sem quedas para o início da MI, o que pode ter favorecido a observação de um numero maior de 
bebês com uma posição mais elevada dos braços no início da MI, fazendo sentido a hipótese anterior.

$O$ fato de os bebês apresentarem um valor do $A B$ maior no início da MI pode, também, ser explicado pelo controle dos graus de liberdade na realização de um movimento mais complexo. Pesquisadores como Whitall e Getchell ${ }^{34}$, ressaltaram que existem vários caminhos ou graus de liberdade no sistema que se alteram e tendem a se auto-organizarem em alguns padrôes simples e distintos. LEDEBT ${ }^{2}$ indicou a redução dos graus de liberdade quando os bebês, em seu estudo, iniciaram com posição mais elevada dos braços vindos a abaixá-los ao longo do tempo. Além disso, Newell e McDonalD ${ }^{35}$ sugerem que o empenho para resolver o problema dos graus de liberdade é restringido por necessitar-se de dois requisitos de controle: manter simultaneamente a exploração da nova tarefa e preservar a postura do corpo.

Assim, de maneira geral, as duas variáveis (CP e $\mathrm{AB})$ sofreram grandes modificaçóes até a quarta sessão, aproximadamente dois meses, nas quais os bebês apresentaram mais dificuldades em se locomover não sendo capazes, ainda, de manter regularidade na marcha, sendo as maiores alteraçóes no CP. Segundo Brenière e BrIL ${ }^{36}$, essa instabilidade na locomoção observado no início da MI nos bebês pode ter sido devido ao fato de eles não terem desenvolvido forças musculares suficientes até o quinto mês da MI, supondo-se que fatores desenvolvimentais, como a falta de força, possa ser uma das causas da maior instabilidade dos bebês ${ }^{5,37-38}$. Esse pode ter sido um fator que levou os bebês, em nosso estudo, a demonstrar maiores alteraçóes nas quatro primeiras sessóes na superfície deformante, dificultando o padrão da marcha em relação à superfície rígida durante a aquisição da MI, exigindo assim, dos bebês, mais força para a elevação das pernas para complementação do ciclo de passada e para uma maior adaptação dos membros superiores, uma vez que, a característica da superfície deformante foi responsável pelo "afundamento" dos bebês a cada contato com o pé nessa superfície, devido ao peso corporal. A partir destes resultados, supóe-se que os bebês melhoraram o padrão de marcha, primeiro, na superfície rígida e que, ao longo das oito sessóes, houve melhora no padrão de marcha para as duas superfícies, pois todos os participantes finalizaram a oitava sessão com um $\mathrm{CP}$ maior e um $\mathrm{AB}$ menor.

$\mathrm{O}$ objetivo desse estudo foi investigar se a mudança no ambiente poderia alterar os parâmetros de membros inferiores (CP) e membros superiores (AB) durante a aquisição da MI. Os resultados observados demonstraram que os bebês apresentaram um CP maior ao longo das sessóes melhorando sua locomoção e um AB menor, indicando que ao final das sessóes, todos os bebês já se encontravam com os braços estendidos ao longo do corpo. Além disso, esses resultados indicam que os valores do CP e do $\mathrm{AB}$ se "estabilizaram" primeiro na superfície rígida, ressaltando o efeito adaptativo que a restrição do ambiente surtiu nas variáveis e influenciando no tempo de estabilização delas, demonstrando que, o período de aquisição da marcha compreende um processo de modulação motora dinâmica, cujo resultado é a adequação das competências à nova demanda ou tarefa $^{33}$. De acordo com os resultados encontrados na FIGURA 5, os bebês melhoraram o padrão da marcha primeiro na superfície rígida e ao longo das oito sessóes, houve melhora no padrão de marcha para as variáveis $\mathrm{CP}$ e $\mathrm{AB}$ nas duas superfícies, pois todos os participantes finalizaram a oitava sessão com um CP maior e um AB menor (FIGURAS 3 e 6).

Estas observaçôes condizem com a ideia de que a restrição do ambiente influencia na organização da resposta do $\mathrm{CP}$ e do $\mathrm{AB}$ dos bebês e que as alteraçóes das variáveis mostraram que a marcha durante a iniciação envolve movimentos de ambas as partes, superior e inferior do corpo, como uma unidade.

\section{Nota}

As autoras Vanessa Mota Andrade-de Castro e Raquel de Melo Martins são alunas do Programa de Pós-Graduação associado em Educação Física da UEM/UEL. 


\section{Abstract}

Effect of instability of the surface in the stride length and angle of the arm of babies during the gait acquisition

The acquisition of independent gait was analyzed using a longitudinal study examining the effect of instability of the surface in stride length and angle of the arm of eleven babies, with mean age of $12.09 \pm$ 0.42 months. The babies were followed for 4 months with biweekly assessments. The gait was conducted on two independent surface conditions - rigid and deforming. The stride length and angle of the arm were analyzed by Kinematics, using the program APAS. The results showed a significant effect on the factors "collections" and "surface" in stride length and significant effect on the factor "collections" in the arm angle, indicating changes in the behavior of the gait in two variables. The data indicate a developmental change incurred during the acquisition of independent gait and suggests that these changes precede the selection of a pattern or a strategy best suited to the demands of the environment.

KEY WORDS: Independent gait; Child development; Biomechanics; Baby.

\section{Referências}

1. Bril B, Brenière Y. Postural requirements and progression velocity in young walkers. J Mot Behav. 1992; 24:105-15.

2. Ledebt A. Changes in arm posture during the early acquisition of walking. Infant Behav Dev. 2000; 23:78-9.

3. Badaly D, Adolph KE. Beyond the average: walking infants take steps longer than their leg length. Infant Behav Dev. 2008;31:554-8.

4. Hallemans A, De Clercq D, Dhanis L, Aerts, P. Changes in mechanical control of movement during the first 15 monts of independent walking; a longitudinal study. J Mot Behav. 2007;39:227-38.

5. Thelen E. Development of coordinated movement: implications for early human development. In: Wade MG, Whiting HTA, editors. Motor skills acquisition. Dordrecht: Nijhoff; 1986. p.107-24.

6. Okamoto T, Okamoto K. Electromyographic characteristics at the onset of independent walking in infancy. Electromyogr Clin Neurophysiol. 2001;41:33-41.

7. Bril B, Brenière Y. Posture and independent locomotion in early childhood: learning to walk or learning dynamic postural control? In: Savelsberg G. The development of co-ordination in infancy. Amsterdam: Elsevier; 1993. p.337-58.

8. Clark JE, Phillips SJ. A longitudinal study of intralimb coordination in the first year of independent walking: a dynamical systems analysis. Child Dev. 1993;64:1143-57.

9. Sutherland DH, Olshen R, Cooper L, Woo SL. The development of mature gait. J Bone Joint Surg. 1980;62-A:336-53.

10. Dierick F, Lefebvre C, van den Hecke A. Development of displacement of centre of mass during independent walking in children. Dev Med Child Neurol. 2004;46:533-9.

11. Holt KG, Fonseca ST, Lafiandra ME. The dynamics of gait in children with spastic hemiplegic cerebral palsy: theoretical and clinical implications. Hum Mov Sci. 2000;19:375-405.

12. Thelen E, Ulrich BD. Hidden skills: a dynamic systems analysis of treadmill stepping during the first year. Monogr Soc Res Child Dev. 1991;56:1-103.

13. Hallemans A, De Clercq D, Otten B, Aerts P. 3D dynamics of walking in toddlers: a cross-sectionstudy spanning the first rapid de development phase of walking. Gait Posture. 2005;22:107-18.

14. Rodriguez EB, Chagas PSC, Silva PLP, Kirkwood RN, Mancini MC. Impact of leg length and body mass on the stride length and gait speed of infants with normal motor development: a longitudinal study. Braz J Phys Ther. 2013;17:163-9.

15. Cheron G, Bouillot E, Dan B, Bengoetxea A, Draye JP, Lacquaniti F. Development of a kinematic coordination pattern in toddler locomotion: planar covariation. Exp Brain Res. 2001;137:455-66.

16. Elftman H. The function of the arms in walking. Hum Biol. 1939;11:529-36.

17. Murray MP. Gait as a total patterns of movement. Am J Phys Med. 1967;46:290-333.

18. Burnett CN, Johnson EW. Development of gait in childhood: part II. Dev Med Child Neurol. 1971;13:207-15.

19. Masayoshi K, Ulrich B. A biomechanical analysis of the high guard position of arms during walking in toddlers. Infant Behav Dev. 2006;29:509-27. 
20. Adolph KE. Psychophysical assessment of toddler's ability to cope with slopes. J Exp Psychol Hum Percept Perform. 1995;21:734-90.

21. Vereijken B, Pedersen AV, Storken JH. Early independent walking: a longitudinal study of load perturbation effects. Dev Psychobiol. 2009;51:374-83.

22. Theveniau N, Boisgontier MP, Varieras S, Olivier I. The effects of clothes on independent walking in toddlers. Gait Posture. 2014;39:659-61.

23. Ledebt $\mathrm{A}$, Brenière $\mathrm{Y}$. Dynamical implication of anatomical and mechanical parameters in gait initiation process in children. Hum Mov Sci. 1994;13:801-15.

24. Okamoto T, Okamoto K, Andrew PD. Electromyographic developmental changes in one individual from newborn stepping to mature walking. Gait Posture. 2003;17:18-23.

25. Chagas PSC, Mancini MC, Fonseca ST, Soares TBC, Gomes VPD, Sampaio RF. Neuromuscular mechanisms and anthropometric modifications in the initial stages of independent gait. Gait Posture. 2006;24:375-81.

26. Yaguramaki N, Kimura T. Acquirement of stability and mobility in infant gait. Gait Posture. 2002;16:69-77.

27. Bortolaia AP. Efeitos da experiência no andar na organização da passada durante a ultrapassagem sobre obstáculos em bebês [dissertação]. Rio Claro (SP): Universidade Estadual Paulista Julio de Mesquita Filho; 2004.

28. Rodriguez EB, Chagas PSC, Silva PLP, Kirkwood RN, Mancini MC. Impact of leg length and body mass on the stride length and gait speed of infants with normal motor development: a longitudinal study. Braz J Phys Ther. 2013;17:163-69.

29. Adolph KE, Eppler MA, Gibson EJ. Crawling versus walking infants' perception of affordances for locomotion over sloping. Child Dev. 1993;64:1158-74.

30. Lima CB, Secco CR, Miyasike VS, Gobbi LTB. Equilíbrio dinâmico: influência das restriçóes ambientais. Rev Bras Cineantropom Desempenho Hum. 2001;3:83-94.

31. Gibson EJ, Riccio G, Schumuckler MA. Detection of the traversability of surfaces by crawling and walking infants. J Exp Psychol Hum Percept Perform. 1987;13:533-44.

32. Payne VG, Isaacs LD. Desenvolvimento motor humano: uma abordagem vitalícia. Rio de Janeiro: Guanabara Koogan; 2007.

33. Kubo M, Ulrich B. A biomechanichal analysis of the 'high guard' position of arms during walking in toddlers. Infant Behav Dev. 2006;29:509-17.

34. Whitall J, Getchell N. From walking to running: applying a dynamical systems approach to the development of locomotor skills. Child Dev. 1995;66:1541-53.

35. Newell KM, McDonald PV. Learning to coordinate redundant biomechanical degrees of freedom. In: Swinnen S, Heuer H, Massion J, Casaer P, editores. Interlimb coordination: neural, dynamical, and cognitive constraints. San Diego: Academic Press; 1993.

36. Brenière Y, Bril B. Development of postural control of gravity forces in children during the first 5 years of walking. Exp Brain Res. 1998;121:255-62.

37. Thelen E. Motor development: a new synthesis. Am Psychol. 1995;50:79-95.

38. Adolph KE, Vereijken B, Shrout PE. What changes in infant walking and why? Child Dev. 2003;74:475-97.

\section{Agradecimentos}

As autoras agradecem o apoio financeiro do CNPq.

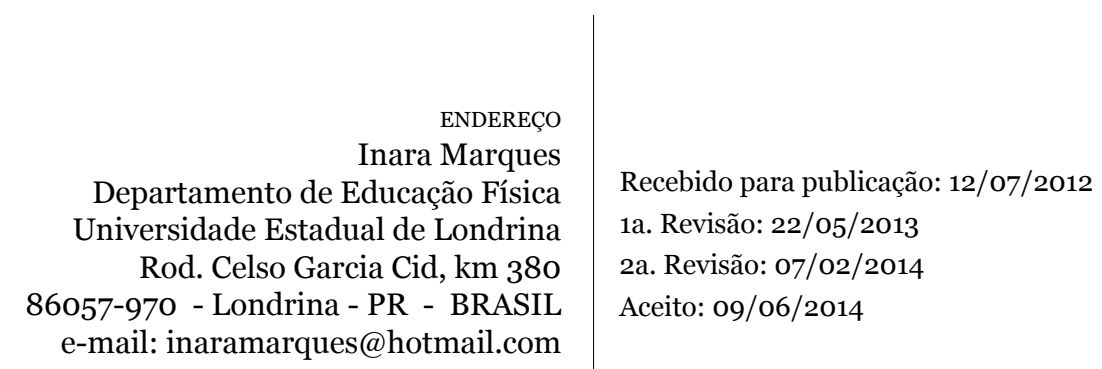

490 • Rev Bras Educ Fís Esporte, (São Paulo) 2014 Jul-Set; 28(3):481-90 